Article

\title{
In Vitro Methods for Predicting Chemical Leukoderma Caused by Quasi-Drug Cosmetics
}

\author{
Lihao Gu ${ }^{1}$, Haifeng Zeng ${ }^{1}$, Tomomi Takahashi ${ }^{1}$ and Kazuhisa Maeda ${ }^{1,2, *}$ \\ 1 Bionics Program, Tokyo University of Technology Graduate School, 1404-1 Katakuramachi, Hachioji City, \\ Tokyo 192-0982, Japan; chaos19901008@gmail.com (L.G.); SteveZeng@hotmail.com (H.Z.); \\ takahashitomomi1024@gmail.com (T.T.) \\ 2 School of Bioscience and Biotechnology, Tokyo University of Technology, 1404-1 Katakuramachi, \\ Hachioji City, Tokyo 192-0982, Japan \\ * Correspondence: kmaeda@stf.teu.ac.jp; Tel.: +81-42-637-2442
}

Received: 27 July 2017; Accepted: 30 August 2017; Published: 2 September 2017; Corrected: 13 June 2022

\begin{abstract}
Skin care cosmetics frequently contain whitening or lightening agents. The present study aimed to establish in vitro methods for predicting chemical leukoderma caused by whitening agents in cosmetics. The risks of chemical leukoderma were predicted based on percutaneous absorption rates, toxic concentrations, and toxicity mechanisms. Thus, in vitro skin permeation rate and cytotoxic concentrations of whitening agents were studied using excised skin and cultured B16 melanoma cells. Pigment cell toxicity was observed using transmission electron microscopy (TEM). The levels of hydroxyl radical $(\cdot \mathrm{OH})$ were measured and the location of $\cdot \mathrm{OH}$ generation sites were determined in cultured B16 melanoma cells. Pigment cells cultured under conditions with high tyrosinase activity developed cytotoxicity when exposed to compounds known to cause leukoderma, while those cultured under conditions with low tyrosinase activity did not. Phenolic compounds that cause leukoderma were applied to the pigment cells at the concentration absorbed percutaneously under conditions with high tyrosinase activity. Cells that were observed using TEM demonstrated a large number of vacuolar degenerations in intracellular melanosomes after treatment with phenolic compounds that are known to cause leukoderma. Hydroxyl radical generation during the tyrosinase reaction was examined, as the whitening agents that inhibit tyrosinase activity serve as tyrosinase substrates. Only phenolic compounds that cause leukoderma generated high amounts of hydroxyl radicals. Thus, the hydroxyl radical is a melanocyte-specific toxin that disrupts tyrosinase-containing melanosomes. Whitening agents that generate high amounts of hydroxyl radicals may cause leukoderma. The in vitro method being reported here can predict the potential of a drug to cause leukoderma and whether the use of a specific whitening agent poses a risk.
\end{abstract}

Keywords: quasi-drug cosmetics; chemical leukoderma; melanocytes; hydroxyl radical

\section{Introduction}

Approximately 20 active ingredients, including hydroquinone- $\beta$-D-glucoside (arbutin, ARB), 4-n-butylresorcinol (4BR), 3-O-ethyl ascorbic acid, tranexamic acid, and 4-methoxysalicylic acid potassium salt (4MSK), have been approved and used in quasi-drug cosmetics in Japan [1-5]. In 2001, product descriptions changed from "preventing dark spots and freckles due to sun damage" to "preventing dark spots and freckles by suppressing melanin production" or "preventing dark spots and freckles by suppressing melanin accumulation" in 2001. Epidermal depigmentation products are typed according to their modes of action. Some inhibit melanin production in melanocytes by inhibiting tyrosinase, the key enzyme in melanin synthesis, or by enhancing the decomposition of tyrosinase to suppress melanin production. Other types are based on suppressing melanosome maturation, transport, and transfer molecules; promoting epidermal metabolism by encouraging 
stratum corneum desquamation and turnover, thus preventing melanin accumulation; and redox breakdown of melanin [5].

For products that inhibit tyrosinase, ingredients such as ARB, $( \pm)$ rhododendron $[( \pm)$ 4-(3-hydroxybutyl) phenol, 4HP], magnolignan (2,2'-dihydroxy-5,5'-dipropyl-biphenyl; ML), 4BR, and 4MSK have been used as active ingredients of quasi-drug cosmetics in Japan. However, as of 4 July 2013, quasi-drug cosmetics containing 4HP were voluntarily recalled after leukoderma was confirmed in people who had used them. There were 19,605 confirmed cases of leukoderma as of 30 November 2016; of these, 11,928 patients have mostly recovered, but many still suffer from the condition even 3 years later [6]. $4 \mathrm{HP}$ is an active ingredient approved by the Ministry of Health, Labour and Welfare under the Pharmaceutical Affairs Law in Japan. This molecule is a reduced form of raspberry ketone (RK), a 4-substituted phenol (para-phenol) that has been previously reported to cause leukoderma [7] and depigmentation in C57 black mice [8]. This information should have provided a warning signal; nevertheless, $4 \mathrm{HP}$ was approved as a quasi-drug cosmetics ingredient. The problem appeared to stem from the in vitro method used. Therefore, specific toxicity to melanocytes could not be evaluated.

The mechanism underlying the pathogenesis of leukoderma appears to be the toxicity of 4-substituted phenols to melanocytes. These phenols are detrimental to tyrosinase and its function in melanosomes or melanin-containing organelles. If the damaging effects are minimized, leukoderma could be reversed. However, in case of roughness, 4-substituted phenol levels may become elevated in the skin or become more toxic. Thus, over the long term, destruction of melanocytes could occur and the leukoderma may become permanent [9-14].

The purpose of this study was to develop an in vitro evaluation method for predicting the occurrence of leukoderma caused by the active ingredient in skin depigmentation quasi-drug cosmetics. Specifically, the method was designed to predict the risk of leukoderma development and was based on mechanisms underlying melanocyte-specific toxicity, common to phenolic compounds that reportedly cause leukoderma. The risks of chemical leukoderma were predicted based on toxicity mechanisms, toxic concentrations, and percutaneous absorption rates. Since many skin care quasi-drug cosmetics are formulated with active ingredients for epidermal depigmentation and are intended to be used daily without limitations on usage or frequency, it is crucial that they do not cause leukoderma. The evaluation scheme developed in this study is proposed to be used as another appraisal tool to confirm that a skin depigmentation product poses little or no risk of causing leukoderma.

\section{Materials and Methods}

\subsection{Materials}

We purchased 4HP from Wako Pure Chemical Industries, Ltd. (Osaka, Japan); ARB and 4BR from Tokyo Chemical Industry Co., Ltd. (Tokyo, Japan); RK and 4-methoxysalicylic acid (4MS) from Sigma-Aldrich Corp. (St. Louis, MO, USA); and ML from Funakoshi Co., Ltd. (Tokyo, Japan). 4MSK was used as the potassium salt of 4MS. Other reagents used were analytical grade and obtained from Wako Pure Chemical Industries, Ltd.

Melanocyte-specific toxicity of $4 \mathrm{HP}$ and RK, common to phenolic compounds that are known to cause leukoderma, were used as positive controls.

\subsection{Measurements of Skin Concentrations of Test Ingredients}

The octanol-water partition coefficients $(K o / w)$ of the test ingredients were measured [15] and skin permeability coefficients determined using Potts \& Guy's skin permeation coefficient prediction equation (Equation (1)) [16]. The in vitro skin permeation rate was determined in frozen samples of excised skin of hairless mouse (Laboskin ${ }^{\circledR}$, Hos:HR-1, male, 7 weeks of age, Hoshino Laboratory Animals, Inc., Ibaraki, Japan) in a diffusion cell using Fick's first law of diffusion (Equation (2)) [17] applied to a skin area of $1.5 \mathrm{~cm}^{2}$ and then the rate was divided by wet skin weight to obtain 
the concentration in the skin. National guidelines were followed for the care and use of our laboratory animals.

Potts \& Guy's skin permeation coefficient prediction equation:

$$
\log P(P \text { in cm } / \mathrm{s})=-6.3+0.71 \times \log K o / w-0.0061 \times \mathrm{MW}
$$

Fick's first law of diffusion: $d Q / d t=P C v$

where abbreviations are as follows: MW, molecular weight; $Q$, amount permeated in skin $\left(\mathrm{mg} / \mathrm{cm}^{2}\right) ; t$, time of exposure; $C v$, exposure concentration $\left(\mathrm{mg} / \mathrm{cm}^{3}\right)$.

The octanol-water partition coefficient indicating the degree of lipid solubility (or water solubility) is generally proportional to the permeability coefficient $[18,19]$. Thus, the percutaneous absorption rate of $4 \mathrm{MSK}$ differs depending on the $\mathrm{pH}$ because the octanol-water partition coefficient $\left(K_{o} / w\right)$ changes according to $\mathrm{pH}$ [20]. For $4 \mathrm{MSK}, \mathrm{pKa}=3.31\left(25^{\circ} \mathrm{C}\right)$, and according to the Henderson-Hasselbalch equation (Equation (3)), the $\mathrm{pH}$ of $4 \mathrm{MSK}$ can vary with the ratio of non-ionized molecules that are able to be absorbed percutaneously and ionized molecules that cannot. The aqueous phase was adjusted to pH 6.2 when the octanol-water partition coefficient was determined.

$$
\mathrm{C}_{\text {union }}+\mathrm{C}_{\text {ion }}=\mathrm{C}_{\text {union }}\left(1+10^{\mathrm{pH}-\mathrm{pKa}}\right)
$$

where abbreviations are as follows: $C_{\text {union, }}$ concentration (unionized); $C_{\text {ion, }}$ concentration (ionized).

\subsection{Measurements of Skin Permeation Rate}

A lotion containing the test substance was formulated (contained in $100 \mathrm{~g}$ of lotion: glycerin, $4 \mathrm{~g}$; 1,3-butanediol, 6 g; PEG-60 hydrogenated castor oil, 0.2 g; phenoxyethanol, 0.35 g; test ingredient, potassium hydroxide to adjust the $\mathrm{pH}$ to 6.2, with the remainder deionized water). In $100 \mathrm{~g}$ of lotion, the test ingredient was 4HP (2 g), ML (0.5 g), ARB (7 g), 4BR (0.3 g), or 4MSK (3 g).

The dorsal skin from hairless mice was mounted in a Franz diffusion cell (with $37^{\circ} \mathrm{C}$ constant temperature circulating water), and $15 \mu \mathrm{L}$ of lotion containing the test ingredient was applied to the skin $\left(1.5 \mathrm{~cm}^{2}\right)$. The receptor chamber was stirred with a magnetic stirrer, and $100 \mu \mathrm{L}$ of sample was taken every $20 \mathrm{~min}$ for up to $2 \mathrm{~h}$. Samples were stored at $-30^{\circ} \mathrm{C}$ in the receptor chamber for later measurements of test ingredient concentration by HPLC. The conditions were as follows: CAPCELL PAK C18 $(4.6 \mathrm{~mm} \phi \times 250 \mathrm{~mm})$, column at $40{ }^{\circ} \mathrm{C}$, flow rate $(1.0 \mathrm{~mL} / \mathrm{min})$, and injection volume $(10 \mu \mathrm{L})$. The detection wavelengths and mobile phase were $281 \mathrm{~nm}$ and acetonitrile:0.1\% acetic acid (20:80) for 4HP, $290 \mathrm{~nm}$ and methanol:0.1\% acetic acid (85:15) for ML, $285 \mathrm{~nm}$ and methanol:0.1\% acetic acid (10:90) for ARB, $280 \mathrm{~nm}$ and methanol:0.1\% acetic acid for 4BR (60:40), and $294 \mathrm{~nm}$ and methanol:0.1\% acetic acid (85:15) for $4 \mathrm{MS}$.

A 1-g skin sample was immersed overnight in chloroform: methanol (2:1) to remove the lipid fraction and then placed in a freeze dryer to remove the water, after which the skin dry weight was determined. The skin dry weight subtracted from the wet weight was defined as the solid fraction, and the rest was defined as the fraction in which the test ingredient was dissolved.

\subsection{Measuring Cytotoxic Concentrations of Test Ingredients}

The cloning of B16 melanoma cells (Cell Resource Center for Biomedical Research, Institute of Development, Aging and Cancer, Tohoku University, Sendai, Japan) was performed and cells with high tyrosinase activity and low tyrosinase activities were acquired. In 24-well plates (Thermo Fisher Scientific Inc., Waltham, MA, USA), $7 \times 10^{4}$ B16 melanoma cells with either high or low tyrosinase activity were incubated for $1 \mathrm{~d}$ with $500 \mu \mathrm{L}$ of $10 \%$ bovine serum in Dulbecco's modified Eagle medium (DMEM, Thermo Fisher Scientific Inc.). The test ingredients with 10\% bovine serum in DMEM were then added to the wells and incubated for 3 days. After replacing the culture medium, $50-\mu \mathrm{L}$ samples were placed in a Cell Counting Kit-8 (Dojindo laboratories, Kumamoto, Japan), and 
$2 \mathrm{~h}$ later, the number of viable cells was determined by measuring $450 \mathrm{~nm}$ absorbance using a microplate reader (Multi-Detection Microplate POWERSAN HT, BioTek Instruments Inc., Winooski, $\mathrm{VT}$, USA). The concentrations of $4 \mathrm{HP}, \mathrm{ML}, \mathrm{ARB}, 4 \mathrm{BR}$, and 4MSK were based on previously determined percutaneous absorption amounts. The concentration of RK was the same as that of $4 \mathrm{HP}$. In the 3-day exposure to the cells, final concentrations of the test ingredients in the wells were $600,300,150$, 75, and 37.5 $\mu \mathrm{mol} / \mathrm{L}$ (4HP and RK); 40, 20, 10, 5, and $2.5 \mu \mathrm{mol} / \mathrm{L}$ (ML); 370, 185, 92.5, 46.25, and $23.125 \mu \mathrm{mol} / \mathrm{L}$ (ARB); 1940, 970L, 485, 242, and $121 \mu \mathrm{mol} / \mathrm{L}$ (4MSK); 40, 20, 10, 5, and $2.5 \mu \mathrm{mol} / \mathrm{L}$ (4BR). In the 3-hour-exposure to the cells, final concentrations of the test ingredients in the wells were $1200 \mu \mathrm{mol} / \mathrm{L}, 600 \mu \mathrm{mol} / \mathrm{L}, 300 \mu \mathrm{mol} / \mathrm{L}, 150 \mu \mathrm{mol} / \mathrm{L}$, and $75 \mu \mathrm{mol} / \mathrm{L}(4 \mathrm{HP}$ and RK), $40 \mu \mathrm{mol} / \mathrm{L}$, $20 \mu \mathrm{mol} / \mathrm{L}, 10 \mu \mathrm{mol} / \mathrm{L}, 5 \mu \mathrm{mol} / \mathrm{L}$, and $2.5 \mu \mathrm{mol} / \mathrm{L}(\mathrm{ML}), 800 \mu \mathrm{mol} / \mathrm{L}, 400 \mu \mathrm{mol} / \mathrm{L}, 200 \mu \mathrm{mol} / \mathrm{L}$, $100 \mu \mathrm{mol} / \mathrm{L}$, and $50 \mu \mathrm{mol} / \mathrm{L}$ (ARB), $200 \mu \mathrm{mol} / \mathrm{L}, 100 \mu \mathrm{mol} / \mathrm{L}, 50 \mu \mathrm{mol} / \mathrm{L}, 25 \mu \mathrm{mol} / \mathrm{L}$, and $12.5 \mu \mathrm{mol} / \mathrm{L}$ (4MSK), and $40 \mu \mathrm{mol} / \mathrm{L}, 20 \mu \mathrm{mol} / \mathrm{L}, 10 \mu \mathrm{mol} / \mathrm{L}, 5 \mu \mathrm{mol} / \mathrm{L}$, and $2.5 \mu \mathrm{mol} / \mathrm{L}$ (4BR).

\subsection{Measurements of Cytotoxicity of Test Ingredients in the Presence of Tyrosinase}

In 24-well plates, $1 \times 10^{5}$ B16 melanoma cells were incubated for $1 \mathrm{~d}$ with $500 \mu \mathrm{L}$ of $10 \%$ bovine serum in DMEM. $500 \mu \mathrm{L}$ of $2 \%$ of bovine serum in DMEM with either test ingredient alone, or test ingredient with tyrosinase (mushroom $10 \mathrm{U} / \mathrm{mL}$; Sigma-Aldrich) was then added and the cells incubated for $3 \mathrm{~h}$. After replacing the culture medium, 50- $\mathrm{LL}$ samples were placed in a Cell Counting Kit-8, and $2 \mathrm{~h}$ later the number of viable cells was determined at $450 \mathrm{~nm}$ absorbance with the microplate reader.

\subsection{Observations of Cell Morphology by Transmission Electron Microscopy (TEM)}

The cultured cells were placed in 1.5\% paraformaldehyde and $0.5 \%$ glutaraldehyde in phosphate buffer solution (PBS) at $4{ }^{\circ} \mathrm{C}$ for $1 \mathrm{~h}$. After fixation, the cells were stirred and washed in PBS, centrifuged, post-fixed in $1 \%$ osmium tetroxide, centrifuged again, and the harvested cells were solidified in agar, which was finely sectioned. The samples were then dehydrated though an alcohol series and embedded in Epon epoxy resin to prepare blocks for electron microscopy. Toluidine-blue-stained specimens were prepared. After examination, one block per sample was selected for thin sectioning. The sections were examined using TEM (JEM-140, JEOL Ltd., Tokyo, Japan), and images were taken.

\subsection{Measurements of Hydroxyl Radical $(\cdot \mathrm{OH})$}

In 96-well plates (Thermo Fisher Scientific Inc.), PBS (78 $\mu \mathrm{L})$, test ingredient $(2 \mu \mathrm{L})$, tyrosinase (mushroom $10 \mathrm{U} / \mathrm{mL}$ ) $(10 \mu \mathrm{L}$ ), and hydroxyphenyl fluorescein (HPF; $5 \mu \mathrm{mol} / \mathrm{L}$, Goryo Chemical, Inc., Sapporo, Japan) were added to each plate and allowed to react at $37^{\circ} \mathrm{C}$. The fluorescence intensity of the compound generated by $\cdot \mathrm{OH}$ (excitation, $485 \mathrm{~nm}$; fluorescence, $528 \mathrm{~nm}$ ) was measured every $30 \mathrm{~min}$ from 0 to $240 \mathrm{~min}$ using the fluorescent plate reader (POWERSAN HT). The test ingredient solution was initially $20 \mathrm{mmol} / \mathrm{L}(10 \mathrm{mmol} / \mathrm{L}$ for ML) and was serially diluted with an aqueous solution of $50 \%$ DMSO or DMSO 10 times.

\subsection{Measurements of Hydrogen Peroxide $\left(\mathrm{H}_{2} \mathrm{O}_{2}\right)$}

In 96-well plates, PBS $(78 \mu \mathrm{L})$, test ingredient $(2 \mu \mathrm{L})$, tyrosinase (mushroom $10 \mathrm{U} / \mathrm{mL} ; 10 \mu \mathrm{L}$ ), and $\mathrm{H}_{2}$ DCFDA ( $5 \mathrm{mmol} / \mathrm{L} ; 10 \mu \mathrm{L}$, Thermo Fisher Scientific Inc.) were added to each plate and allowed to react at $37^{\circ} \mathrm{C}$. The fluorescence intensity of the compound generated by $\mathrm{H}_{2} \mathrm{O}_{2}$ (excitation, $485 \mathrm{~nm}$; fluorescence, $528 \mathrm{~nm}$ ) was measured every $30 \mathrm{~min}$ from 0 to $240 \mathrm{~min}$ using the fluorescent plate reader (POWERSAN HT). The test ingredient solution was initially $20 \mathrm{mmol} / \mathrm{L}$ (10 mmol/L for ML) and was serially diluted in an aqueous solution of 50\% DMSO or DMSO 10 times. 


\subsection{Determination of $\cdot \mathrm{OH}$ Generation Sites}

In four-chambered slides (AGC Techno Glass Co., Ltd., Shizuoka, Japan), $3 \times 10^{4}$ B16 melanoma cells were incubated for $1 \mathrm{~d}$ with $400 \mu \mathrm{L}$ of $10 \%$ bovine serum in DMEM. $4 \mathrm{HP}(125 \mu \mathrm{mol} / \mathrm{L})$ with $10 \%$ bovine serum in DMEM was then added, and the cells were incubated for $3 \mathrm{~d}$. HPF $(2 \mu \mathrm{L}$ of $5 \mu \mathrm{mol} / \mathrm{L}$ solution) was added and allowed to react at $37^{\circ} \mathrm{C}$ for $1 \mathrm{~h}$. After fixation in $4 \%$ paraformaldehyde in PBS, the cells were washed with PBS and blocked with $10 \%$ goat serum. The samples were stained with tyrosinase-related protine-1 (TRP-1) using TMH-2 antibodies [21] and the Alexa Fluor 488-labeled anti-rat IgG goat polyclonal antibody. The samples were then observed using a fluorescence microscope, and images were taken.

\subsection{Statistical Analytical Method}

Tests for statistical significance between control and test ingredient were performed with unpaired two-tailed $t$-test in Excel, and $p<0.05$ was considered significant.

\section{Results}

\subsection{Octanol-Water Partition Coefficients (log Ko/w)}

The determination of concentrations of test ingredients in the octanol and water phases indicate the octanol-water partition coefficients $(\log K o / w)$ of $4 \mathrm{HP}, \mathrm{ML}, \mathrm{ARB}, 4 \mathrm{BR}, 4 \mathrm{MS}, 4 \mathrm{MSK}$, and RK, as shown in Table 1. The skin permeability of chemical substances in vivo correlates well with their hydrophobicity and molecular weight. Therefore, $\log \mathrm{Ko} / \mathrm{w}$ and molecular weight are used to predict or determine the skin permeability of chemical substances. In addition, the accumulation of chemical substances in vivo is also related to hydrophobicity. Although the degree depends on the mode of action, toxicity becomes stronger as the hydrophobicity of the chemical substance increases. Furthermore, Potts \& Guy's skin permeability coefficient prediction equation predicts that the skin permeability coefficient increases with an increase in $\log K_{o} / w$ and decreases with an increase in molecular weight [16]. Log Ko/w for the tested substances was $\mathrm{ML}>4 \mathrm{BR}>4 \mathrm{MS}>\mathrm{RK}>4 \mathrm{HP}>\mathrm{ARB}>4 \mathrm{MSK}$, in increasing order. Molecular weight for the tested substances was $\mathrm{RK}<4 \mathrm{HP}=4 \mathrm{BR}<4 \mathrm{MS}<4 \mathrm{MSK}<\mathrm{ML}<\mathrm{ARB}$, in ascending order.

Table 1. Octanol-water partition coefficients $(\log K o / w)$.

\begin{tabular}{cccccccc}
\hline Active Ingredient & 4HP & ML & ARB & 4BR & 4MS & 4MSK & RK \\
\hline $\log K o / w$ & 1.303 & 3.951 & -1.485 & 2.399 & 1.744 & -1.577 & 1.406 \\
$K o / w$ & 20.083 & 8927.841 & 0.033 & 250.336 & 55.416 & 0.026 & 25.495 \\
\hline
\end{tabular}

ARB, arbutin; 4HP, rhododendrol; ML, magnolignan; 4BR, 4-n-butylresorcinol; 4MS, 4-methoxysalicylic acid; 4MSK, 4-methoxysalicylic acid potassium salt; RK, raspberry ketone.

\subsection{Measurements of Skin Concentrations of Test Ingredients}

Skin concentrations of test ingredients were determined from skin permeability coefficients calculated using the Potts \& Guy's skin permeation coefficient prediction equation and Fick's first law of diffusion applied to a skin area of $1.5 \mathrm{~cm}^{2}$ and divided by the skin wet weight (Table 2). As a reference, $7 \% \mathrm{ARB}$ in lotion resulted in a skin concentration of $0.008 \mathrm{mg} / \mathrm{g}$, and $2 \% 4 \mathrm{HP}, 0.5 \% \mathrm{ML}$, and $0.3 \% 4 \mathrm{BR}$ in lotion resulted in concentrations of $0.335,0.735$, and $0.151 \mathrm{mg} / \mathrm{g}$, respectively, all higher than the ARB reference. At $\mathrm{pH} 6.2$, the concentration of the ionized form of $4 \mathrm{MSK}$ was calculated to be approximately $1 \times 10^{3}$ times greater than that of the unionized form; at this $\mathrm{pH}$, the estimated skin concentration of $3 \% 4$ MSK lotion was low $(0.004 \mathrm{mg} / \mathrm{g})$, and almost no percutaneous absorption was observed. Wet skin $(1 \mathrm{~g})$ yielded $0.785 \mathrm{~g}$ of liquid phase when the dry weight was subtracted, and the skin concentrations of $7 \% \mathrm{ARB}, 2 \% 4 \mathrm{HP}, 0.5 \% \mathrm{ML}, 0.3 \% 4 \mathrm{BR}$, and 3\% 4MSK in lotion were determined to be 37.4, 2567, 3461, 1153, and $27.2 \mu \mathrm{mol} / \mathrm{L}$, respectively, after considering the amount of test ingredients dissolved in the lipid-water fraction. 
Table 2. Skin concentrations of test ingredients determined from Potts \& Guy's skin permeation coefficient prediction equation.

\begin{tabular}{cccccc}
\hline Active Ingredient & 4HP & ML & ARB & 4BR & 4MSK \\
\hline Molecular weight & 166.22 & 270.37 & 272.25 & 166.22 & 206.24 \\
Cosmetics formulation of active ingredient $(\mathrm{mg} / \mathrm{g})$ & 20 & 5 & 70 & 3 & 30 \\
Skin concentration $(\mathrm{mg} / \mathrm{g})^{*}$ & 0.335 & 0.735 & 0.008 & 0.151 & 0.004 \\
Estimated skin concentration $(\mu \mathrm{mol} / \mathrm{L})$ & 2567 & 3461 & 37.4 & 1153 & 27.2 \\
\hline
\end{tabular}

* Skin concentrations of test ingredients were calculated from skin permeability coefficients determined using the Potts \& Guy's skin permeation coefficient prediction equation and Fick's first law of diffusion applied to a skin area of $1.5 \mathrm{~cm}^{2}$, divided by the skin wet weight. ARB, arbutin; 4HP, rhododendrol; ML, magnolignan; 4BR, 4-n-butylresorcinol; 4MSK, 4-methoxysalicylic acid potassium salt.

\subsection{Number of Viable Cells after 3-Day-Exposure to Test Ingredients}

The toxicity of the test ingredients to B16 melanoma cells with higher and lower tyrosinase activity after a 3-day exposure is shown in Figure 1. Upon treatment with $4 \mathrm{HP}$ and RK, the viability of low tyrosinase activity cells was higher than that of high tyrosinase activity cells. In the presence of $10 \%$ serum, a high degree of toxicity to both types of cells was observed for 4HP and RK concentrations higher than $150 \mu \mathrm{mol} / \mathrm{L}$. Treatment with $20 \mu \mathrm{mol} / \mathrm{L}$ or $40 \mu \mathrm{mol} / \mathrm{L} \mathrm{ML}$ and $10 \%$ serum resulted in a great decrease in viable cell count, with the number of viable cells being reduced to $10 \%$ of the starting number. Toxicity was not observed in either the low or high tyrosinase activity cells for concentrations below $370 \mu \mathrm{mol} / \mathrm{L}$ ARB or $970 \mu \mathrm{mol} / \mathrm{L}$ 4MSK. For 4BR, toxicity was not observed in either the low or high tyrosinase activity cells at concentrations below $10 \mu \mathrm{mol} / \mathrm{L}$.
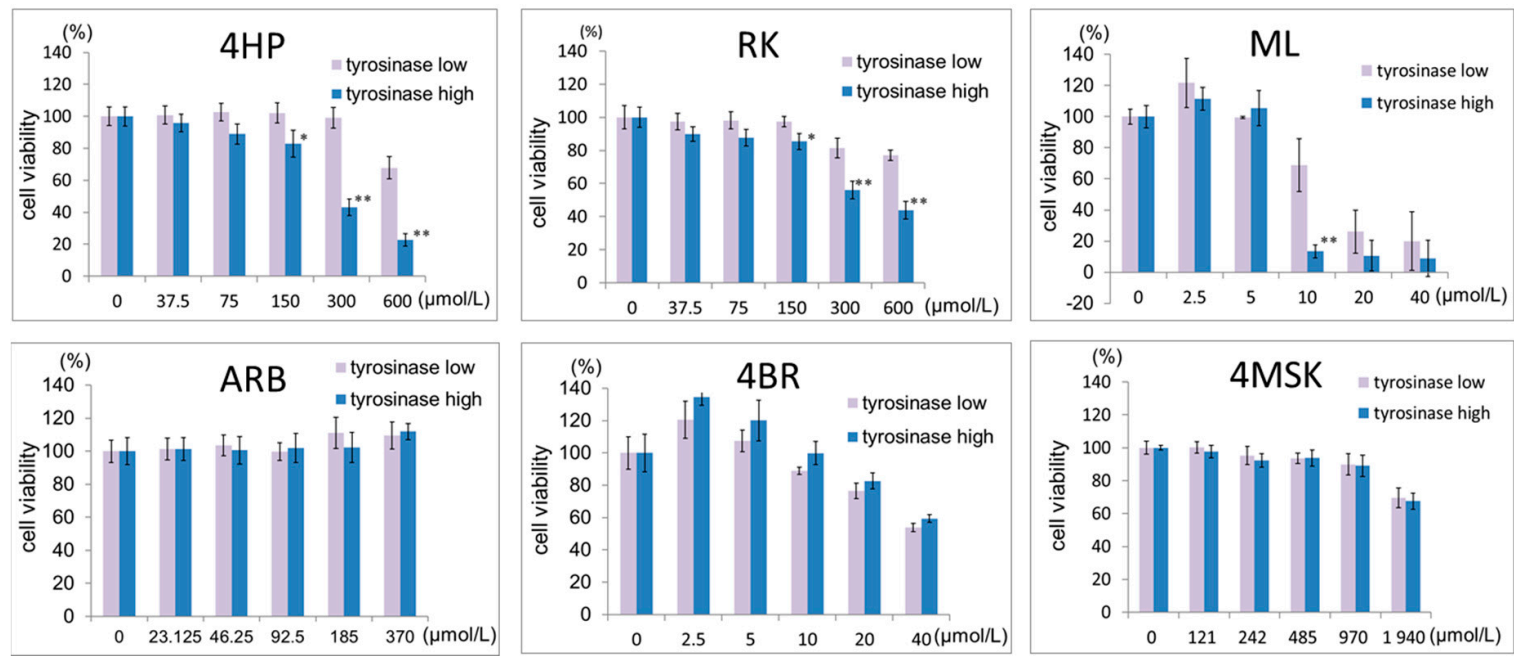

Figure 1. Effects of $4 \mathrm{HP}, \mathrm{RK}, \mathrm{ML}, \mathrm{ARB}, 4 \mathrm{BR}$, and $4 \mathrm{MSK}$ on the number of viable cultured $\mathrm{B} 16$ melanoma cells (3 days after addition). Viable cell numbers are shown, with the control set as $100 \%$. Results are presented as the mean \pm S.D. of three experiments. ${ }^{*} p<0.05$, tyrosinase low vs. tyrosinase high at the same concentration; ${ }^{* *} p<0.01$, tyrosinase low vs. tyrosinase high at the same concentration. $4 \mathrm{HP}$, rhododendrol; RK, raspberry ketone; ML, magnolignan; ARB, arbutin; 4BR, 4-n-butylresorcinol; 4MSK, 4-methoxysalicylic acid potassium salt.

\subsection{Number of Viable Cells after Exposure to Test Ingredients in the Presence of Tyrosinase}

The toxicity of the test ingredients to B16 melanoma cells after a 3-h exposure in the presence or absence of tyrosinase is shown in Figure 2. Treatment with $4 \mathrm{HP}$ or RK at 75-600 $\mu \mathrm{mol} / \mathrm{L}$ with $2 \%$ serum resulted in a concentration-dependent decrease in viable cell counts. At $600 \mu \mathrm{mol} / \mathrm{L}$, the viable cell number was reduced to approximately $20 \%$ of the control. Moreover, in the culture medium containing $2 \%$ serum, a concentration-dependent decrease in the number of viable cells was observed 
in cells treated with ML at concentrations above $20 \mu \mathrm{mol} / \mathrm{L}$. In the presence of tyrosinase, the number of viable cells decreased after treatment with ML at concentrations above $5 \mu \mathrm{mol} / \mathrm{L}$. The number of viable cells did not decrease on treatment with $\mathrm{ARB}, 4 \mathrm{BR}$, or $4 \mathrm{MSK}$ at any of the concentrations tested in the presence of tyrosinase.

The toxicity of $4 \mathrm{HP}$ or RK to pigment cells is shown in the micrographs in Figure 3 . After $3 \mathrm{~h}$, cells exposed to $4 \mathrm{HP}$ or RK at $75 \mu \mathrm{mol} / \mathrm{L}$ became spherical; at $600 \mu \mathrm{mol} / \mathrm{L}$, toxic effects were noted as changes in cell shape occurred. Continued culturing of the cells resulted in spherical cells that peeled off the dish and floated in the medium.
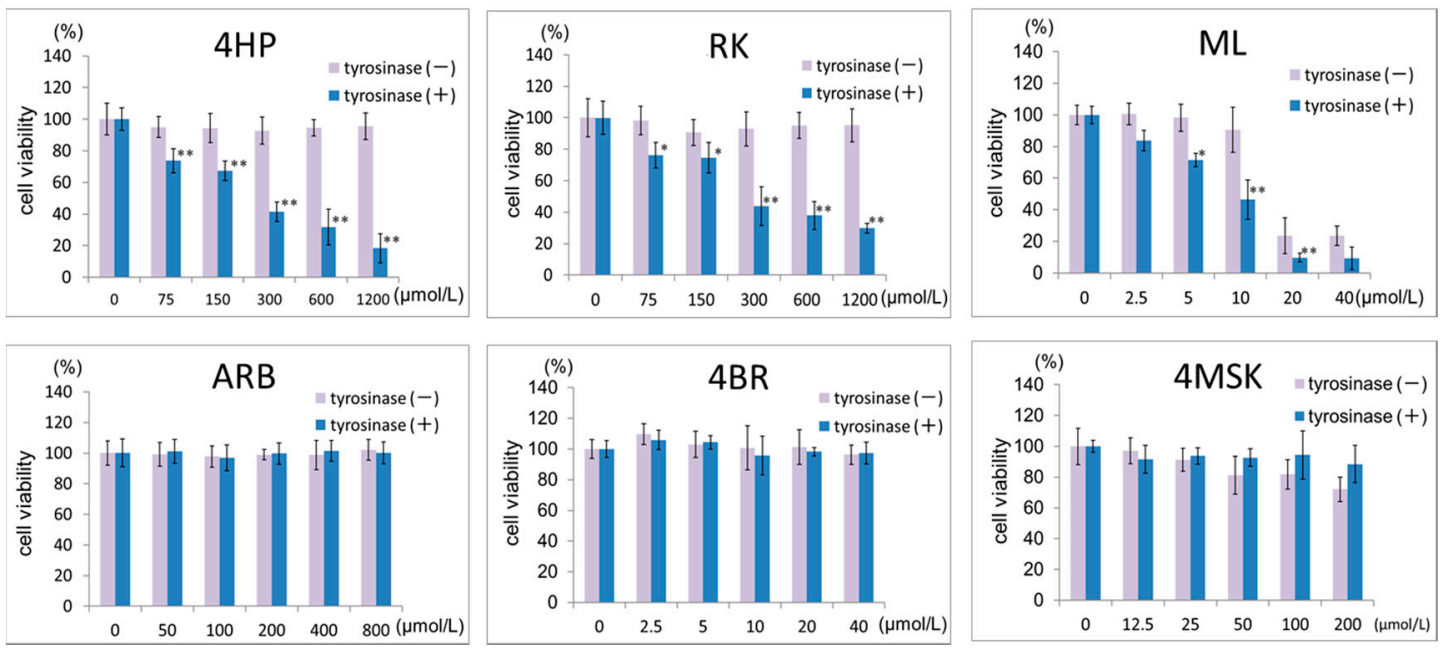

Figure 2. Effects of $4 \mathrm{HP}, \mathrm{RK}, \mathrm{ML}, \mathrm{ARB}, 4 \mathrm{BR}$, and $4 \mathrm{MSK}$ in the presence of tyrosinase on viable cell numbers ( $3 \mathrm{~h}$ after addition). Viable cell numbers are shown, with the control set as $100 \%$. Results are presented as the mean \pm S.D. of three experiments. ${ }^{*} p<0.05$, tyrosinase $(-)$ vs. tyrosinase $(+)$ at the same concentration; ${ }^{* *} p<0.01$, tyrosinase $(-)$ vs. tyrosinase $(+)$ at the same concentration. $4 \mathrm{HP}$, rhododendrol; RK, raspberry ketone; ML, magnolignan; ARB, arbutin; 4BR, 4-n-butylresorcinol; 4MSK, 4-methoxysalicylic acid potassium salt.

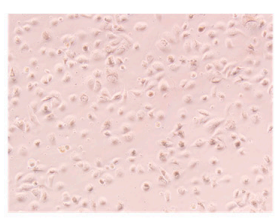

tyrosinase (-)

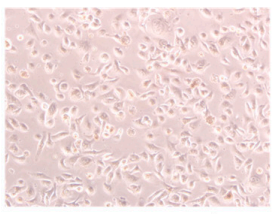

4HP $75 \mu \mathrm{mol} / \mathrm{L}$

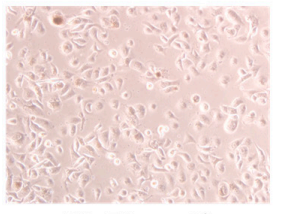

RK $75 \mu \mathrm{mol} / \mathrm{L}$

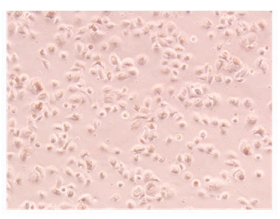

tyrosinase $(+)$

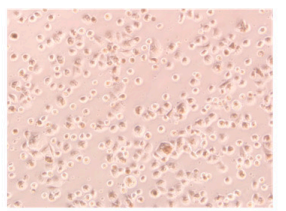

tyrosinase $+4 \mathrm{HP} 75 \mu \mathrm{mol} / \mathrm{L}$

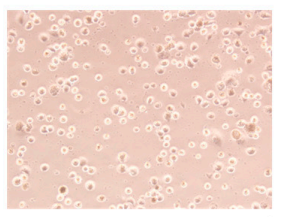

tyrosinase + RK $75 \mu \mathrm{mol} / \mathrm{L}$

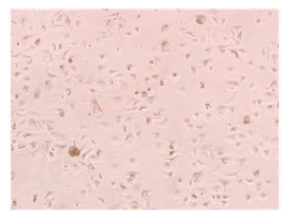

4HP $600 \mu \mathrm{mol} / \mathrm{L}$

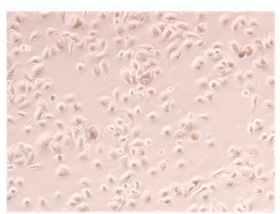

RK $600 \mu \mathrm{mol} / \mathrm{L}$
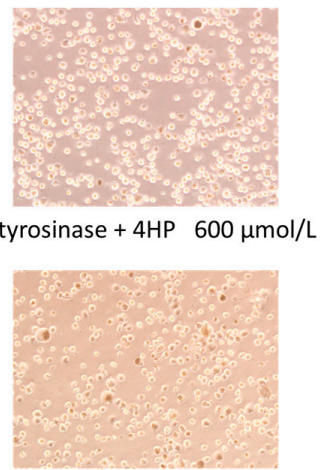

tyrosinase + RK $600 \mu \mathrm{mol} / \mathrm{L}$

Figure 3. Micrographs of pigment cells showing cytotoxicity of $4 \mathrm{HP}$ and RK. Micrographs taken $3 \mathrm{~h}$ after $4 \mathrm{HP}(150 \mu \mathrm{mol} / \mathrm{L})$ or RK $(150 \mu \mathrm{mol} / \mathrm{L})$, with or without tyrosinase added to the medium. $4 \mathrm{HP}$, rhododendrol; RK, raspberry ketone. 


\subsection{In Vitro Factor of Safety and Factor of Effectiveness for Tested Substances}

Using the skin permeability coefficient prediction of Potts \& Guy, the estimated skin concentration was calculated at steady state, along with hydroxyl radical generation (Table 3). The in vitro factor of safety, calculated as B16 melanoma cytotoxic concentration/estimated skin concentration, for 7\% $\mathrm{ARB}, 0.3 \%$ 4BR, and 3\% 4MSK lotions were 25, 0.21, and 100, respectively. These values indicate a high degree of safety assurance for lotions formulated with 7\% ARB or 3\% 4MSK, and cytotoxic effects were not observed in the melanocytes. In contrast, the in vitro factor of safety for $2 \% 4 \mathrm{HP}$ and $0.5 \% \mathrm{ML}$ was 0.13 and 0.07 , respectively, indicating a very low degree of safety.

The in vitro factor of effectiveness, calculated as the estimated skin concentration/melanin inhibitory concentration in B16 cells, for 7\% ARB and 0.3\% 4BR lotions was 0.32 and 92.77, respectively. These values indicate a high degree of effectiveness for $0.3 \% 4 \mathrm{BR}$ and a moderate degree of effectiveness for $7 \%$ ARB. The inhibition of melanin production can also be expected with the application of lotion formulated with $7 \%$ ARB or $0.3 \% 4 \mathrm{BR}$. However, the cytotoxicity concentration and melanin inhibitory concentration in B16 cells are equal to those of the lotion formulated with the $2 \% 4 \mathrm{HP}$ and $0.5 \% \mathrm{ML}$, respectively, indicating a very low degree of effectiveness.

Table 3. In vitro B16 melanoma cytotoxicity concentration/estimated skin concentration and risk of hydroxyl radical generation.

\begin{tabular}{|c|c|c|c|c|c|}
\hline Active Ingredient & $4 \mathrm{HP}$ & ML & ARB & 4BR & 4MSK \\
\hline Melanin inhibitory concentration in B16 cells $(\mu \mathrm{mol} / \mathrm{L})$ & 253 & 20 & 92 & 10 & 970 \\
\hline Estimated skin concentration/Melanin inhibitory concentration in B16 cells & 7.98 & 13.61 & 0.32 & 92.77 & 0.02 \\
\hline Hydroxyl radical generation at the estimated skin concentration & High & High & Low & No & No \\
\hline
\end{tabular}

4HP, rhododendrol; ML, magnolignan; ARB, arbutin; 4BR, 4-n-butylresorcinol; 4MSK, 4-methoxysalicylic acid potassium salt.

\subsection{Observation by TEM}

Electron micrographs of pigment cells exposed to $4 \mathrm{HP}(125 \mu \mathrm{mol} / \mathrm{L}), \mathrm{RK}(125 \mu \mathrm{mol} / \mathrm{L}), \mathrm{ML}$ $(25 \mu \mathrm{mol} / \mathrm{L})$, and $4 \mathrm{BR}(50 \mu \mathrm{mol} / \mathrm{L})$ are shown in Figure 4 . Frequent vacuolization was noted as a cytotoxic feature caused by the accumulation of $4 \mathrm{HP}(125 \mu \mathrm{mol} / \mathrm{L}), \mathrm{RK}(125 \mu \mathrm{mol} / \mathrm{L})$, and $\mathrm{ML}$ ( $25 \mu \mathrm{mol} / \mathrm{L})$. Pigment cells exposed to 4BR $(50 \mu \mathrm{mol} / \mathrm{L})$ were similar to the controls, and cytotoxic features were not observed.

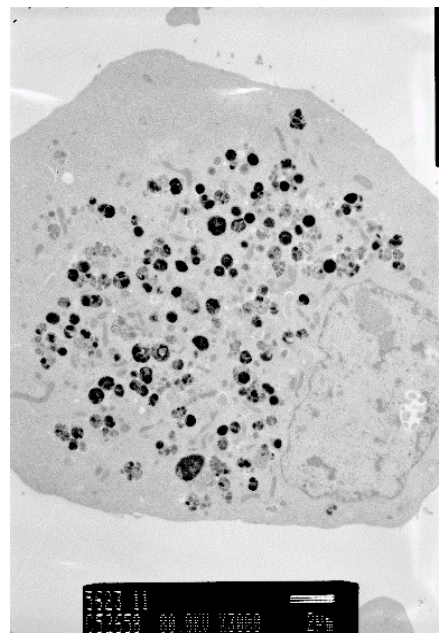

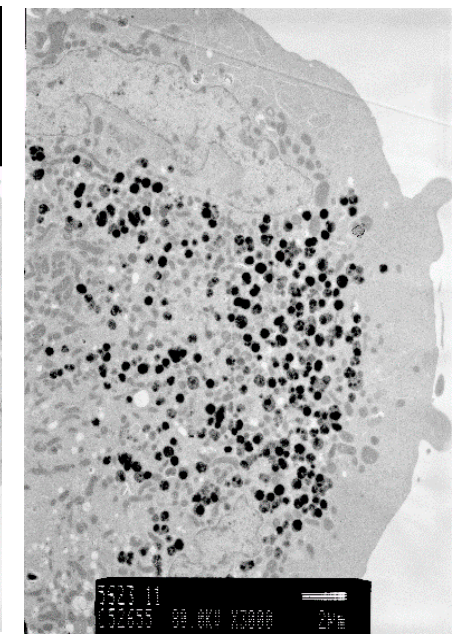

(a)

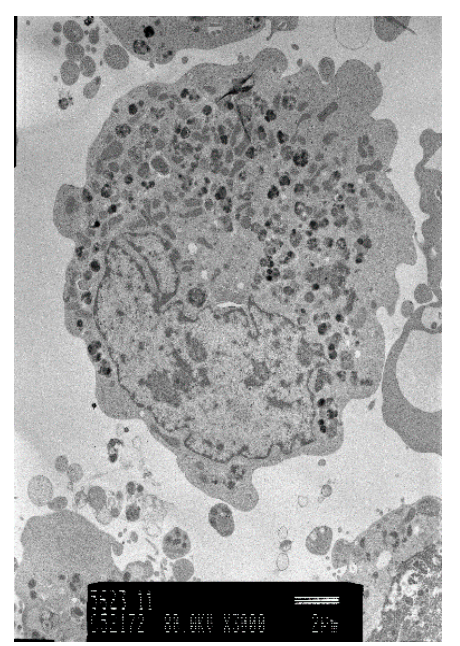

Figure 4. Cont. 

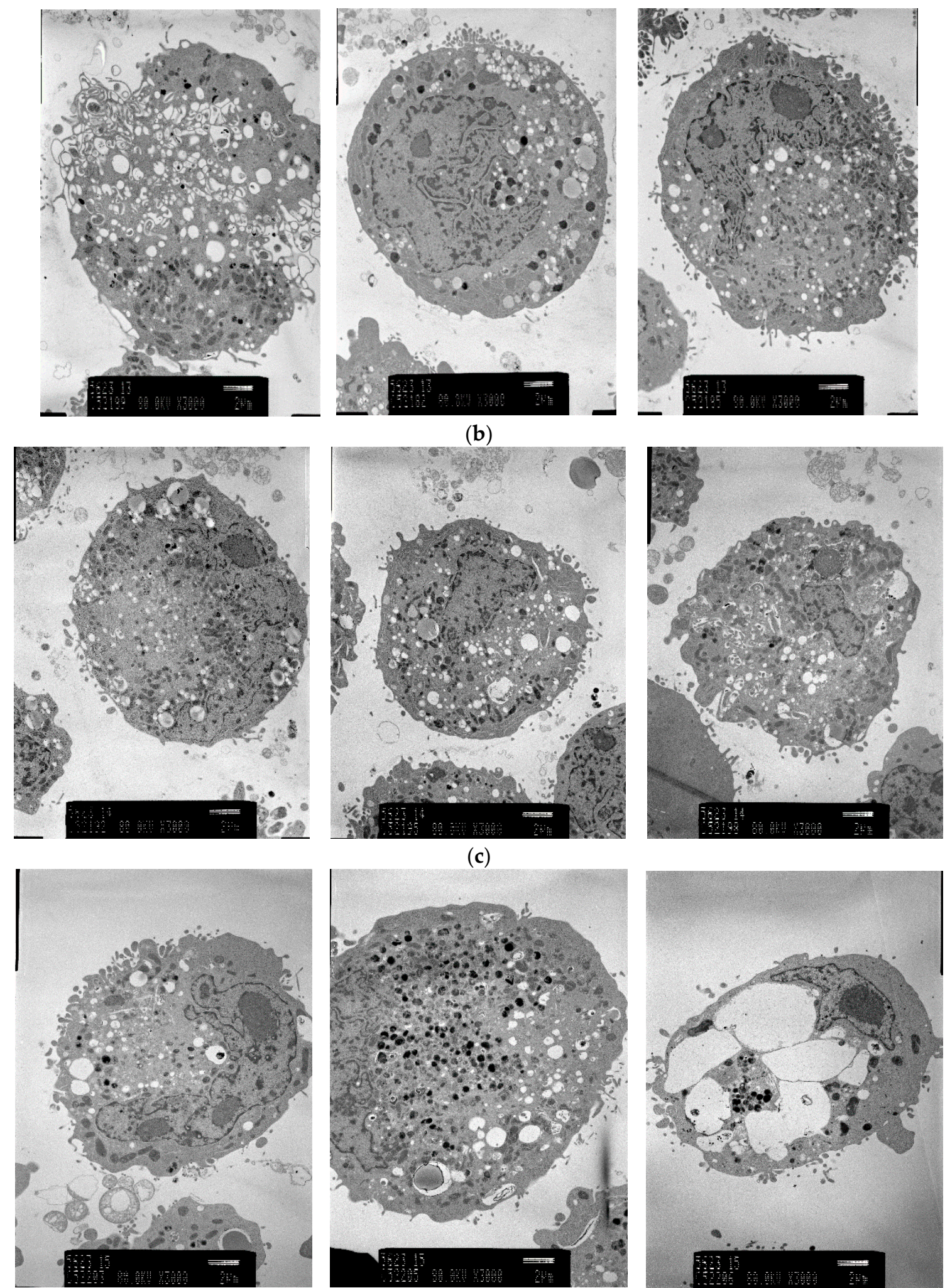

(c)
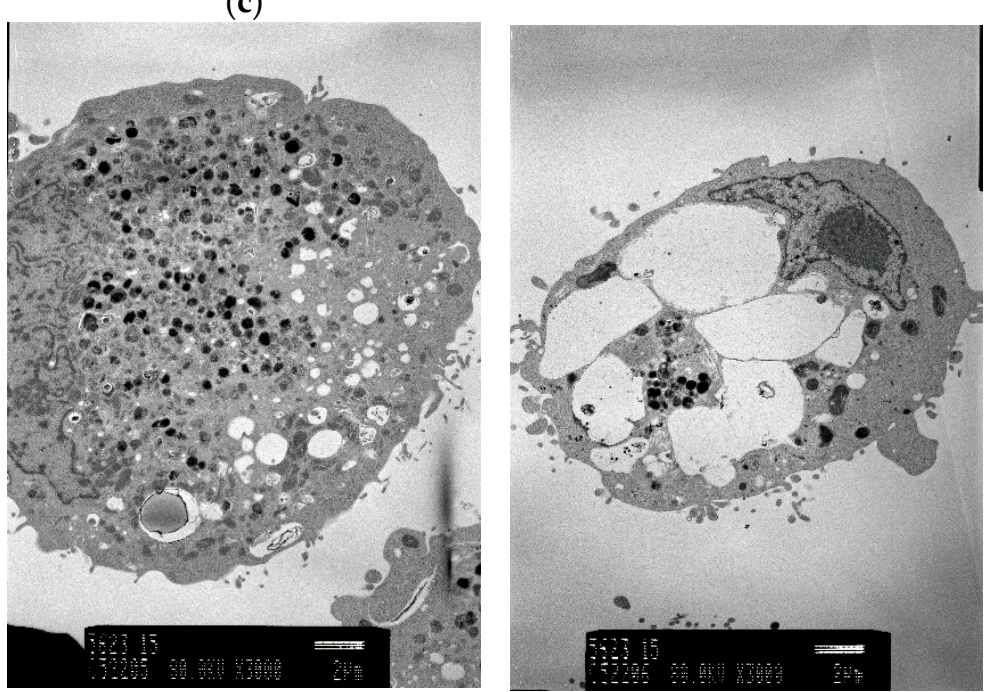

(d)

Figure 4. Cont. 

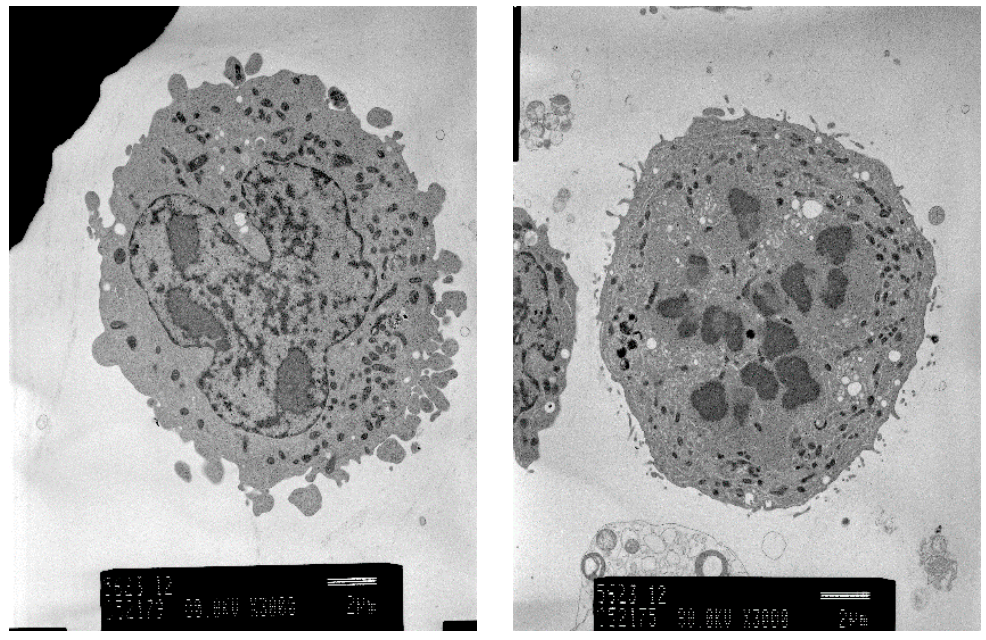

(e)

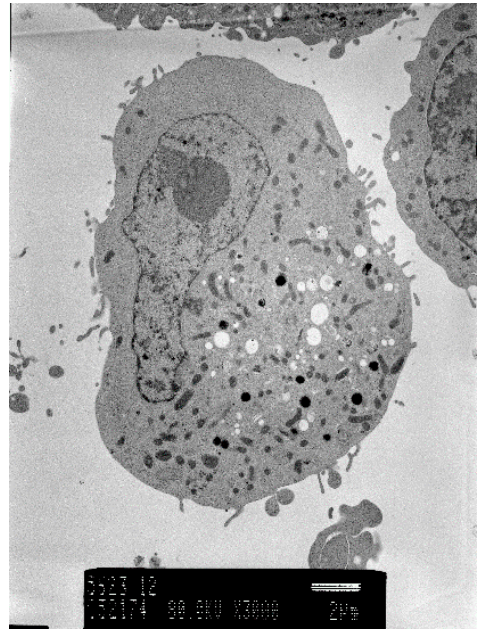

Figure 4. Electron micrographs $(3000 \times)$ of pigment cells treated with $4 \mathrm{HP}(125 \mu \mathrm{mol} / \mathrm{L})$, RK $(125 \mu \mathrm{mol} / \mathrm{L}), \mathrm{ML}(25 \mu \mathrm{mol} / \mathrm{L})$, or 4BR $(50 \mu \mathrm{mol} / \mathrm{L}) .4 \mathrm{HP}$, rhododendrol; RK, raspberry ketone;

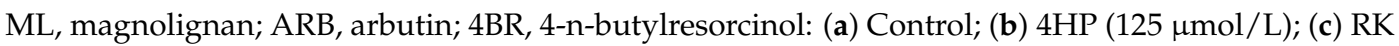
(125 $\mathrm{mol} / \mathrm{L})$; (d) ML $(25 \mu \mathrm{mol} / \mathrm{L})$; (e) 4BR $(50 \mu \mathrm{mol} / \mathrm{L})$.

\subsection{Hydroxyl Radical (·OH) Generation from Test Ingredients in the Presence of Tyrosinase}

A graph comparing $\cdot \mathrm{OH}$ generation by active test ingredients in the presence of tyrosinase after $30 \mathrm{~min}$ is shown in Figure 5. 4HP, RK, and ML were found to generate $\cdot \mathrm{OH}$ in a concentration-dependent manner in the presence of tyrosinase, peaking at $30 \mathrm{~min}$ and then remaining constant. Compared to controls, $\cdot \mathrm{OH}$ generation from $3 \mu \mathrm{mol} / \mathrm{L} 4 \mathrm{HP}$ was 5 times greater and that from $300 \mu \mathrm{mol} / \mathrm{L}$ was 10 times greater. RK and ML at $200 \mu \mathrm{mol} / \mathrm{L}$ also produced $\cdot \mathrm{OH} 10$ times that in the controls. In addition, abundant $\cdot \mathrm{OH}$ generation was detected at concentrations lower than the estimated skin concentrations of $4 \mathrm{HP}(2567 \mu \mathrm{mol} / \mathrm{L})$ and ML $(3461 \mu \mathrm{mol} / \mathrm{L}) . \cdot \mathrm{OH}$ generation from ARB at the estimated skin concentration $(37.4 \mu \mathrm{mol} / \mathrm{L})$ was small, approximately 2 times greater than that in the control. The $\cdot \mathrm{OH}$ generation was not observed at the estimated skin concentrations of 4BR $(1805 \mu \mathrm{mol} / \mathrm{L})$ or $4 \mathrm{MSK}(581 \mu \mathrm{mol} / \mathrm{L})$. There is no risk of leukoderma by treatment with the lotions containing $7 \% \mathrm{ARB}, 0.3 \% 4 \mathrm{BR}$, or $3 \% 4 \mathrm{MSK}$ as determined by the amount of $\cdot \mathrm{OH}$ generated in the presence of tyrosinase at the estimated skin concentration (Table 3). However, there is a risk of leukoderma posed by treatment with the lotion containing $2 \% 4 \mathrm{HP}$ or $0.5 \% \mathrm{ML}$, as determined by the amount of $\cdot \mathrm{OH}$ generated in the presence of tyrosinase at the estimated skin concentration (Table 3). 


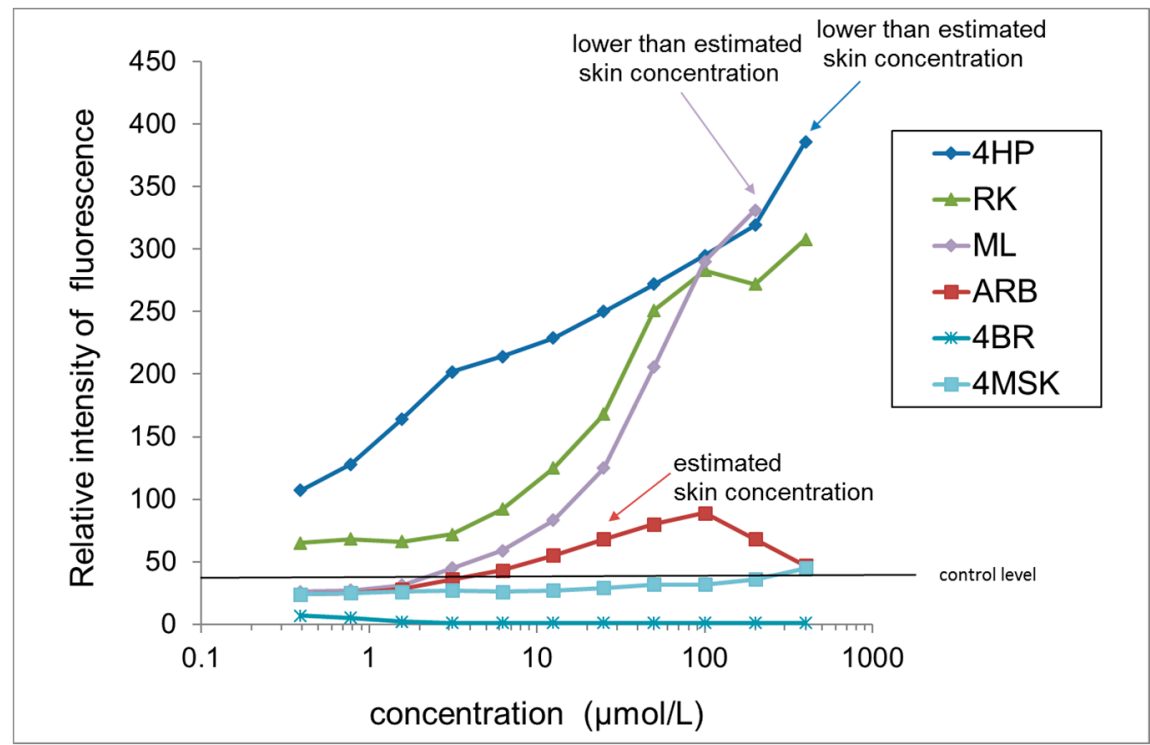

Figure 5. Comparison of $\cdot \mathrm{OH}$ generation by test ingredients in the presence of tyrosinase. Results are presented as the mean of three experiments. $4 \mathrm{HP}$, rhododendrol; RK, raspberry ketone; $\mathrm{ML}$, magnolignan; ARB, arbutin; 4BR, 4-n-butylresorcinol; 4MSK, 4-methoxysalicylic acid potassium salt.

\section{8. $\mathrm{H}_{2} \mathrm{O}_{2}$ Generation by Test Ingredients in the Presence of Tyrosinase}

A graph comparing $\mathrm{H}_{2} \mathrm{O}_{2}$ generation from test ingredients in the presence of tyrosinase after $240 \mathrm{~min}$ is shown in Figure 6. RK and $4 \mathrm{HP}$ generated abundant $\mathrm{H}_{2} \mathrm{O}_{2} \cdot \mathrm{H}_{2} \mathrm{O}_{2}$ generation by $\mathrm{RK}$ was concentration dependent, with $50 \mu \mathrm{mol} / \mathrm{L}$ RK producing 13 times more $\mathrm{H}_{2} \mathrm{O}_{2}$ than controls and $400 \mu \mathrm{mol} / \mathrm{L}$ producing 21 times more. $\mathrm{H}_{2} \mathrm{O}_{2}$ generation by $4 \mathrm{HP}$ was concentration dependent, with $400 \mu \mathrm{mol} / \mathrm{L} 4 \mathrm{HP}$ yielding 9 times more $\mathrm{H}_{2} \mathrm{O}_{2}$ than the control. In the presence of tyrosinase, the amount of $\mathrm{H}_{2} \mathrm{O}_{2}$ generated from $\mathrm{RK}$ and $4 \mathrm{HP}$ began rising after reacting for $60 \mathrm{~min}$, then increased proportionally with reaction time. Only a small amount of $\mathrm{H}_{2} \mathrm{O}_{2}$ was generated by $A R B$, and no $\mathrm{H}_{2} \mathrm{O}_{2}$ generation was observed upon treatment with ML, 4BR, or 4MSK.

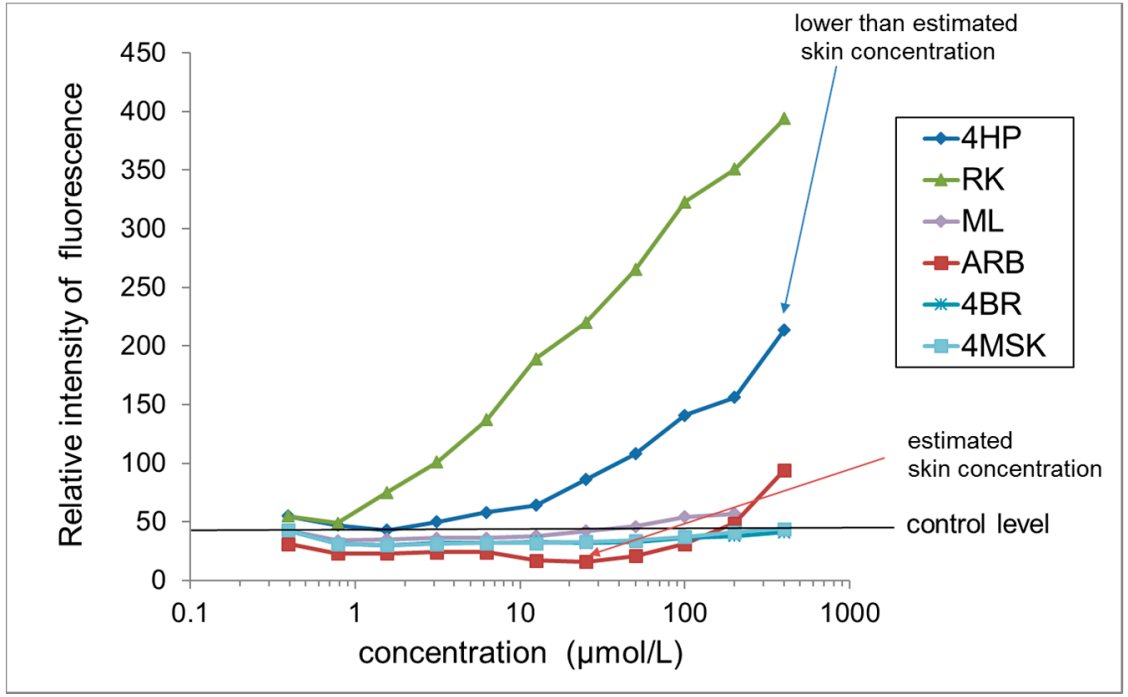

Figure 6. Comparison of $\mathrm{H}_{2} \mathrm{O}_{2}$ generation by test ingredients in the presence of tyrosinase. Results are presented as the mean of three experiments. $4 \mathrm{HP}$, rhododendrol; RK, raspberry ketone; ML, magnolignan; ARB, arbutin; 4BR, 4-n-butylresorcinol; 4MSK, 4-methoxysalicylic acid potassium salt. 


\subsection{Determination of $\cdot \mathrm{OH}$ Generation Sites}

The sites of $\cdot \mathrm{OH}$ generation in B16 melanoma cells treated with $4 \mathrm{HP}$ are shown in Figure 7. Green fluorescently labeled $\cdot \mathrm{OH}$ co-localized with red anti-TRP-1 antibody-stained melanosomes. $\cdot \mathrm{OH}$ generated from $4 \mathrm{HP}$ was confined to melanosomes, and large amounts of highly toxic $\cdot \mathrm{OH}$ were found where tyrosinase was present.
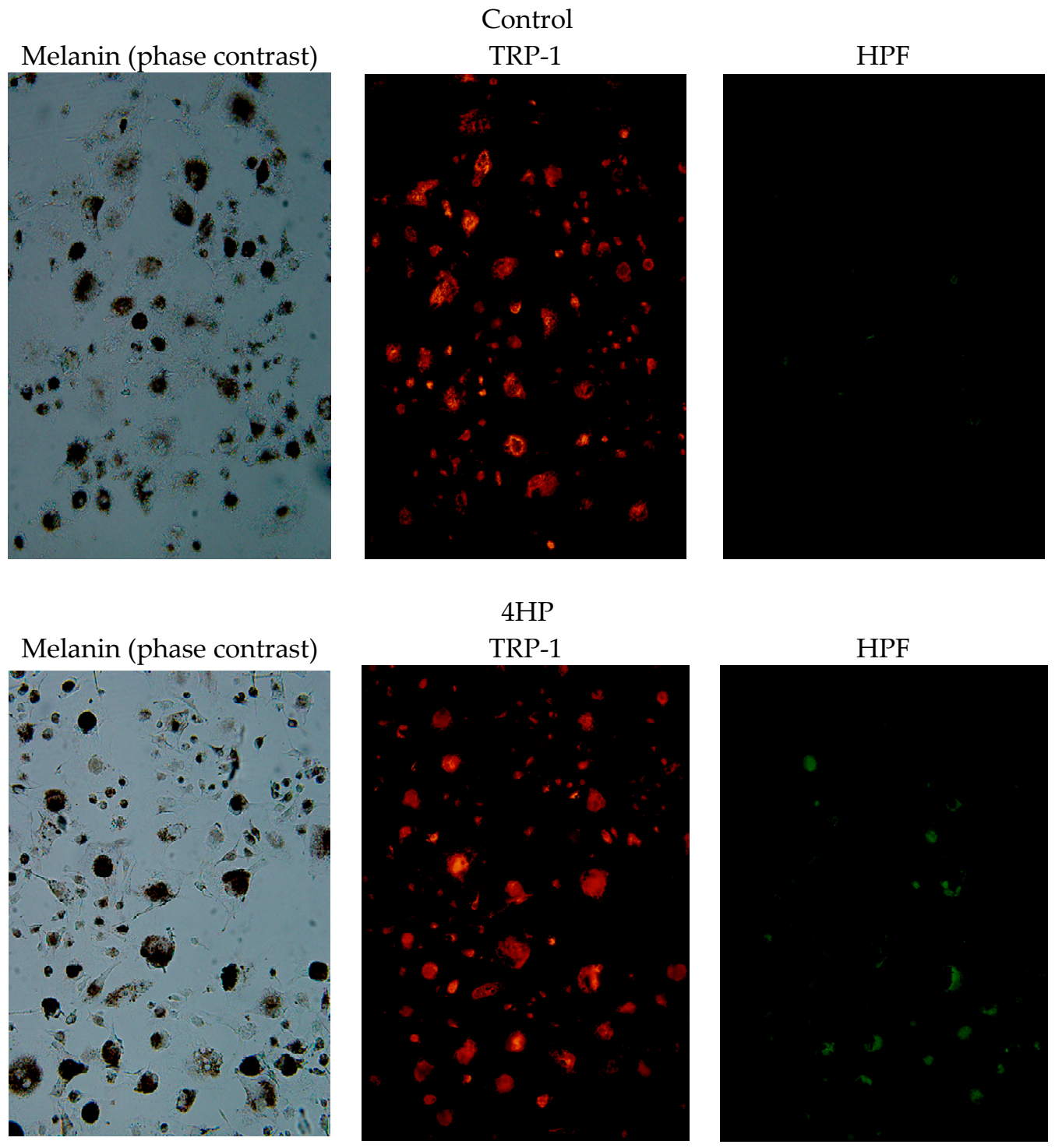

Figure 7. Hydroxy radical $(\cdot \mathrm{OH})$ generation sites in B16 melanoma cells treated with $4 \mathrm{HP}$. Melanin (phase contrast); Red, anti-TRP-1 antibody-stained melanosomes; Green, fluorescently labeled ·OH by HPF. 4HP, rhododendrol; TRP-1, tyrosinase-related protein-1; HPF, hydroxyphenyl fluorescein.

\section{Discussion}

In chemical leukoderma, premelanosomes are destroyed and melanocytes subsequently disappear, causing the symptom of skin depigmentation. A study of the mechanism of leukoderma reported that for RK in B16F10 melanoma cells expressing tyrosinase, the half maximal inhibitory concentration $\left(\mathrm{IC}_{50}\right)$, the concentration at which the cell viability is reduced to $50 \%$, was $0.13 \mathrm{mmol} / \mathrm{L}$. The $\mathrm{IC}_{50}$ of $\mathrm{RK}$ in HT1080 non-pigmented cells (a transformed human fibrosarcoma cell line) without tyrosinase was $1.56 \mathrm{mmol} / \mathrm{L}$ [22]. According to a previous study, the presence of tyrosinase increases the cytotoxicity of RK and the leukoderma caused by RK is not due to the inhibition of melanin biosynthesis, but rather 
the destruction of melanocytes by a toxic substance produced by RK with tyrosinase [22]. Similarly, skin depigmentation caused by topical application of 30\% 4HP solution for 21 days may occur via selective melanocyte toxicity and re-pigmentation occurred approximately 50 days after the application was discontinued in black guinea pigs [23]. However, complete depigmentation was not accomplished because the max $\mathrm{L}^{*}$ value was observed to be 46 and many melanocytes may have reproduced with hair growth and reproduction in that study [23], so re-pigmentation may have occurred in the guinea pigs. In this study, leukoderma caused by $4 \mathrm{HP}$ is not due to inhibition of melanin biosynthesis but rather due to the destruction of melanocytes by a toxic substance produced by $4 \mathrm{HP}$ with tyrosinase.

The structure of the chemical substance that causes leukoderma has been characterized as a 4-substituted phenol having an alkyl group with a nonpolar side chain attached to the 4-position and hydroxylated at the 1-position of the benzene ring. 4HP and its oxidized form, RK, which causes leukoderma, has strong $\cdot \mathrm{OH}$-generating activity in the presence of tyrosinase. Furthermore, it was found that ML also has strong -OH-generating activity. These compounds are both 4-substituted phenols, indicating that there is structural similarity. On the other hand, ARB, which is a glycoside of hydroquinone, demonstrated weak $\cdot \mathrm{OH}$-generating activity, while $4 \mathrm{BR}$, which has resorcinol structure, did not.

The melanocyte-specific toxicity of 4-substituted phenols is caused by the ortho-quinone or ortho-quinone methide generated by the catalytic action of tyrosinase [24-29]. If $4 \mathrm{HP}$ is used as a substrate for tyrosinase, the reaction produces $\cdot \mathrm{OH}$, which is a known melanocyte-specific toxin. Our study results indicate that at least for $4 \mathrm{HP}$ and its oxidized form RK, previously reported to cause leukoderma, the generation of $\cdot \mathrm{OH}$ increases in the presence of tyrosinase.

The mechanism of $\cdot \mathrm{OH}$ production appears to be a Fenton reaction occurring between the liberated $\mathrm{H}_{2} \mathrm{O}_{2}$ and $\mathrm{Cu}(\mathrm{I})-\mathrm{Cu}(\mathrm{I})$ of tyrosinase, generating $\cdot \mathrm{OH}$ by the following reaction (Equation (4)):

$$
\mathrm{Cu}(\mathrm{I})-\mathrm{Cu}(\mathrm{I})+\frac{1}{2} \mathrm{H}_{2} \mathrm{O}_{2} \rightarrow \mathrm{Cu}(\mathrm{II})-\mathrm{Cu}(\mathrm{II})+\frac{1}{2} \mathrm{OH}^{-}+\frac{1}{2} \cdot \mathrm{OH}
$$

Muñoz-Muñoz et al. discussed the production of $\mathrm{H}_{2} \mathrm{O}_{2}$ from 4-substituted phenols in the presence of tyrosinase [30]. When $\mathrm{C}-1$ of the hydroxyl group is bonded to $\mathrm{Cu}$ (II) of the tyrosinase catalytic site and an electron-withdrawing group of $\mathrm{C}-4$ as in $\mathrm{RK}$ is present, the charge density of $\mathrm{Cu}$ (II) increases and affects the hydroxyl group of $\mathrm{C}-2$, causing deprotonation of $\mathrm{C}-2$ [30]. The protons are transferred to a tyrosinase catalytic site peroxide $(\mathrm{OOH})$, generating $\mathrm{H}_{2} \mathrm{O}_{2}$. In contrast, if an electron donating group (e.g., $\mathrm{COOH}, \mathrm{NH}_{2}$ ) is present at $\mathrm{C}-4$, as in tyrosine, which is the starting amino acid of melanin synthesis, the charge density of $\mathrm{Cu}(\mathrm{II})$ in the tyrosinase catalytic site decreases. In this case, the hydroxyl group protons of C-2 are transferred to a histidine residue of the enzyme, and $\mathrm{H}_{2} \mathrm{O}_{2}$ is not generated. The C-4 of RK is an electron-withdrawing group (3-oxobutyl), and the phenolic hydroxyl group of RK binds to the divalent copper $\mathrm{Cu}$ (II) of the catalytic site of tyrosinase, converting it to catechols. When oxidized to ortho-quinones and released, divalent copper $\mathrm{Cu}$ (II) is reduced to monovalent copper $\mathrm{Cu}(\mathrm{I})$, and $\mathrm{H}_{2} \mathrm{O}_{2}$ is generated.

Cytotoxicity is observed with $4 \mathrm{HP}$ or its oxidized form $\mathrm{RK}$, and both $\cdot \mathrm{OH}$ and $\mathrm{H}_{2} \mathrm{O}_{2}$ are generated in the presence of tyrosinase. Moreover, although cytotoxicity is observed with ML treatment in the presence of tyrosinase, $\cdot \mathrm{OH}$ but not $\mathrm{H}_{2} \mathrm{O}_{2}$ is generated. Our results indicate that at least for $4 \mathrm{HP}$, $\mathrm{RK}$, and $\mathrm{ML}$, the increased $\cdot \mathrm{OH}$ generation in the presence of tyrosinase, but not $\mathrm{H}_{2} \mathrm{O}_{2}$ production, is involved in the cytotoxicity. The mechanism is thought to involve the Fenton reaction, in which the $\mathrm{Cu}$ of tyrosinase acts as a catalyst in $\cdot \mathrm{OH}$ generation. Because $\mathrm{H}_{2} \mathrm{O}_{2}$ is not produced, it cannot be used to evaluate the potential of substances that cause chemical leukoderma in melanocytes; instead, $\cdot \mathrm{OH}$ generation should be used for such evaluations. The amounts of ${ }^{1} \mathrm{O}_{2}$ generated via rhododendrol and rhododendrol-catechol oxidations with mushroom tyrosinase were reported [31], and they were probably lower than that of ${ }^{1} \mathrm{O}_{2}$ exhibiting cell toxicity [31]. The calculation of cell volume was erroneous in this previous report [31]; however, ${ }^{1} \mathrm{O}_{2}$ was produced by L-tyrosine and 
L-DOPA in the presence of tyrosinase. These findings suggest that ${ }^{1} \mathrm{O}_{2}$ generated via rhododendrol and rhododendrol-catechol oxidations with tyrosinase does not cause cell toxicity.

Using the skin permeability coefficient prediction equation of Potts \& Guy, the estimated skin concentration calculated at steady state and risk for developing leukoderma was determined. In vitro B16 melanoma cytotoxicity concentration/estimated skin concentration values for the ingredients $4 \mathrm{HP}$ and ML were less than 0.2, indicating a low degree of safety assurance. Cytotoxicity was observed at concentrations much lower than the minimum concentration to be used on the skin. At the skin concentrations tested, $\cdot \mathrm{OH}$ generation increased, and it is likely that the skin becomes lightened due to cytotoxicity to melanocytes. In contrast, the in vitro B16 melanoma cytotoxicity concentration/estimated skin concentration values for the ingredients ARB and 4MSK were greater than 10, indicating a high degree of safety assurance. Cytotoxicity was not observed in pigment cells at the skin concentrations tested, and minimal $\cdot \mathrm{OH}$ generation was noted, indicating that the risk of causing leukoderma was low. 4MSK is ionized at $\mathrm{pH}$ 6.2; thus, its skin permeability is low, and the degree of safety assurance is high. The cytotoxic effects to pigment cells at the skin concentrations tested were minimal. Further, no $\cdot \mathrm{OH}$ generation was observed, suggesting that there was no risk of causing leukoderma.

Active ingredients in quasi-drug cosmetics in Japan must have a high degree of safety, and any detrimental effects must be minimized. Thus, an evaluation method that indicates the cytotoxicity of an ingredient at a given skin concentration may be useful. The results of this study suggest that, in vitro, the suppression of melanin production depends on the inhibition of tyrosinase activity and that concentrations that do not induce cytotoxic effects nor melanin production are required for product safety. ARB and 4MSK satisfied these conditions, but 4HP and ML did not. It is clear that $4 \mathrm{HP}$ and ML do not fulfill Japanese quasi-drug cosmetics standards for safety. The cytotoxicity of 4HP and ML was greater in the presence of $2 \%$ serum than in $10 \%$ serum. These molecules may bind to serum proteins, such that as the serum percentage increases, the availability of $4 \mathrm{HP}$ or ML decreases, thereby diminishing the toxic effect.

In the presence of tyrosinase, $4 \mathrm{HP}$ can be converted into catechols, which are reported as the main cause of cytotoxicity [32]. However, catechols seem to be responsible for approximately $1 / 10$ of the effects observed in $4 \mathrm{HP}$-treated samples. The cytotoxic effects of $4 \mathrm{HP}$ thus cannot be explained by catechol involvement alone. Furthermore, it can be seen from Figure $4 \mathrm{~B}$ in the reference [32] that the cytotoxicity to melanocytes is $0.617 \mathrm{mmol} / \mathrm{L}$, corresponding to $100 \mu \mathrm{g} / \mathrm{mL}$, indicating that $4 \mathrm{HP}$ is cytotoxic to melanocytes at the skin concentration when it is applied at $2 \%$.

This study confirmed that $4 \mathrm{HP}, \mathrm{RK}$, and ML react with tyrosinase substrate to generate high amounts of $\cdot \mathrm{OH}$, thereby exerting toxic effects on melanocytes. Past reports have indicated that the first position in the benzene ring becomes hydroxylated, and 4-substituted alkyl phenols where an alkyl group of nonpolar side chains is attached at the 4-position, are implicated in causing leukoderma. Leukoderma often appears after the occurrence of contact dermatitis. With skin irritation, percutaneous absorption increases and damage from leukoderma becomes more severe. $4 \mathrm{HP}$ is also a 4-substituted phenol; thus, it is expected to cause leukoderma. Melanocyte toxicity of 4-substituted phenols have been reported to be caused by ortho-quinones or ortho-quinone methides catalyzed by tyrosinase, but at low concentrations, tyrosinase enhances $\cdot \mathrm{OH}$ generation and this appears to be the main factor responsible for toxicity is the melanosome. However, Figure 6 shows that $\cdot \mathrm{OH}$ is not necessarily generated in all melanosomes of Stage IV cells, so the mechanism of generation/elimination of $\cdot \mathrm{OH}$ in melanosomes should be considered.

The skin depigmentation agents investigated in this study that produced high amounts of $\cdot \mathrm{OH}$ at the estimated skin concentrations are 4HP and ML. 4HP appears to cause leukoderma, and ML has a similar effect. Thus, caution is required in using these ingredients, taking into consideration the previous report concerning allergic contact dermatitis by ML [33-35]. Electron micrographs of B16 melanoma cells with leukoderma-causing $4 \mathrm{HP}$, RK, and ML treatment show large numbers of vacuoles within cell melanosomes. Skin care cosmetics frequently contain whitening or lightening agents. They 
are routinely applied by adult women without limitations on usage or frequency. Thus, measures should be taken to prevent their adverse effects in the form of chemical leukoderma. Mild leukoderma may be cured. However, the concentrations of these agents in the skin are increased by roughness, resulting in marked toxicity. Prolonged exposure to these agents is cytotoxic to melanocytes, causing permanent leukoderma. Further, pigment cells cultured under conditions of high but not low tyrosinase activity demonstrated decreased viability when exposed to ingredients previously known to cause leukoderma. Thus, the in vitro evaluation method reported in this study may be used as an indicator of whether a given substance will cause leukoderma. B16 melanoma cells are generally used to support test validity and analyze the mechanism of quasi-drugs; they are also adopted as the approval test of the Ministry of Health, Labour and Welfare in Japan. However, together with the test result in a normal human melanocyte in culture medium without phorbol myristate acetate or cholera toxin, it is necessary to consider the mechanism of leukoderma from now on.

\section{Conclusions}

This study further clarifies the mechanisms of action and epidermal concentrations required of ingredients that are toxic to melanocytes, subsequently causing leukoderma. Loss of melanocytes can follow the destruction of premelanosomes by $\cdot \mathrm{OH}$ generated by tyrosinase-mediated reactions. The result is depigmentation of the skin, manifested clinically as leukoderma. This study suggests that the mechanism by which leukoderma onset occurs is the tyrosinase-mediated production of high amounts of $\cdot \mathrm{OH}$; which damages melanosomes and in turn causes the apoptosis of melanocytes. The in vitro evaluation method developed here may be used to determine whether a given ingredient will cause leukoderma.

Acknowledgments: The authors gratefully acknowledge the technical assistance of Michika Higuchi and Kanako Gunji. The study was supported by a grant from the JSPS KAKENHI Grant Number 16K00766.

Author Contributions: L.G., H.Z., T.T., and K.M. carried out the experiments. K.M. designed the study and carried out the analysis. L.G. and K.M. interpreted the data and drafted the manuscript. K.M. supervised the progress and critically revised the manuscript. All authors have read and approved the final manuscript.

Conflicts of Interest: The authors declare no conflict of interest.

\section{References}

1. Maeda, K.; Fukuda, M. Arbutin: Mechanism of its depigmenting action in human melanocyte culture. J. Pharmacol. Exp. Ther. 1996, 276, 765-769. [PubMed]

2. Maeda, K.; Naganuma, M. Topical trans-4-aminomethylcyclohexanecarboxylic acid prevents ultraviolet radiation-induced pigmentation. J. Photochem. Photobiol. B 1998, 47, 136-141. [CrossRef]

3. Maeda, K.; Inoue, Y.; Nishikawa, H.; Miki, S.; Urushibata, O.; Miki, T.; Hatao, M. Involvement of melanin monomers in the skin persistent UVA-pigmentation and effectiveness of vitamin $C$ ethyl on UVA-pigmentation. J. Jpn. Cosmet. Sci. Soc. 2003, 27, 257-268. (In Japanese)

4. Kim, D.S.; Kim, S.Y.; Park, S.H.; Choi, Y.G.; Kwon, S.B.; Kim, M.K.; Na, J.I.; Youn, S.W.; Park, K.C. Inhibitory effects of 4-n-butylresorcinol on tyrosinase activity and melanin synthesis. Biol. Pharm. Bull. 2005, 28, 2216-2219. [CrossRef] [PubMed]

5. Maeda, K. Advances in development of skin whitening agents. Fragr. J. 2008, 36, 65-67. (In Japanese)

6. Homepage of Kanebo Cosmetics, Inc. The Number of Checks of the White spots' Condition, and Recovery, a Reconciliation Situation/the Number of Object Recall. Available online: http:/ / www.kanebo-cosmetics. jp/information/correspondence/data_2016.html (accessed on 16 April 2017).

7. Fukuda, Y.; Nagano, M.; Futatsuka, M. Occupational leukoderma in workers engaged in 4-(p-hydroxyphenyl)-2-butanone manufacturing. J. Occup. Health 1998, 40, 118-122. [CrossRef]

8. Fukuda, Y.; Nagano, M.; Arimatsu, Y.; Futatsuka, M. An experimental study on depigmenting activity of 4-(phydroxyphenyl)-2-butanone in C57 black mice. J. Occup. Health 1998, 40, 97-102. [CrossRef]

9. Saruta, T.; Nakamizo, Y. Leukoplakia due to para-tertiary butyl phenol. Rinsho Derma (Tokyo) 1974, 16, 161-170. (In Japanese) 
10. James, O.; Mayes, R.W.; Stevenson, C.J. Occupational vitiligo induced by p-tert-butylphenol, a systemic disease? Lancet 1977, 2, 1217-1219. [CrossRef]

11. Ebner, V.H.; Helletzgruber, M.; Höfer, R.; Kolbe, H.; Weissel, M.; Winker, N. Vitiligo from p-tert-butylphenol; a contribution to the problem of the internal manifestations of this occupational disease. Derm. Beruf Umw. 1979, 27, 99-104.

12. Budde, V.J.; Stary, A. Skin and systemic disease caused by occupational contact with p-tert-butylphenol: Case reports. Derm. Beruf Umw. 1988, 36, 17-19.

13. Rodermund, O.E.; Jorgens, H.; Muller, R.; Marsteller, H.J. Systemic changes in occupational viyiligo. Hautarzt 1975, 26, 312-316. [PubMed]

14. Ikeda, M.; Ohtsuji, H.; Miyahara, S. Two cases of leucoderma, presumably due to nonyl or octylphenol in synthetic detergents. Ind. Health (Kawasaki) 1970, 8, 192-196. [CrossRef]

15. Albert, L.; Corwin, H.; David, E. Partition coefficients and their uses. Chem. Rev. 1971, 71, 525-616.

16. Potts, R.O.; Guy, R.H. Predicting skin permeability. Pharm. Res. 1992, 9, 663-669. [CrossRef] [PubMed]

17. Siddiqui, O. Physicochemical, physiological, and mathematical considerations in optimizing percutaneous absorption of drugs. Crit. Rev. Ther. Drug Carr. Syst. 1989, 6, 1-38.

18. Blank, I.H.; Scheuplein, R.J.; MacFarlane, D.J. Mechanism of percutaneous absorption. 3. The effect of temperature on the transport of non-electrolytes across the skin. J. Investig. Dermatol. 1967, 49, 582-589. [CrossRef] [PubMed]

19. Cordero, J.A.; Alarcon, L.; Escribano, E.; Obach, R.; Domenech, J. A comparative study of the transdermal penetration of a series of nonsteroidal antiinflammatory drugs. J. Pharm. Sci. 1997, 86, 503-508. [CrossRef] [PubMed]

20. Oakley, D.M.; Swarbrick, J. Effects of ionization on the percutaneous absorption of drugs: Partitioning of nicotine into organic liquids and hydrated stratum corneum. J. Pharm. Sci. 1987, 76, 866-871. [CrossRef] [PubMed]

21. Tomita, Y.; Shibahara, S.; Takeda, A.; Okinaga, S.; Matsunaga, J.; Tagami, H. The monoclonal antibodies TMH-1 and TMH-2 specifically bind to a protein encoded at the murine b-locus, not to the authentic tyrosinase encoded at the c-locus. J. Investig. Dermatol. 1991, 96, 500-504. [CrossRef] [PubMed]

22. Fukuda, Y.; Nagano, M.; Tsukamoto, K.; Futatsuka, M. In Vitro studies on the depigmenting activity of 4-(p-hydroxyphenyl)-2-butanone. J. Occup. Health 1998, 40, 137-142. [CrossRef]

23. Kuroda, Y.; Takahashi, Y.; Sakaguchi, H.; Matsunaga, K.; Suzuki, T. Depigmentation of the skin induced by 4-(4-hydroxyphenyl)-2-butanol is spontaneous re-pigmented in brown and black guinea pigs. J. Toxicol. Sci. 2014, 39, 615-623. [CrossRef] [PubMed]

24. Naish-Byfield, S.; Cooksey, C.J.; Latter, A.M.; Jhonson, C.I.; Riley, P.A. In vitro assessment of the structure-activity relationship of tyrosinase-dependent cytotoxicity of a series of substituted phenols. Melanoma Res. 1991, 1, 273-287. [CrossRef] [PubMed]

25. Riley, P.A.; Cooksey, C.J.; Johnson, C.I.; Land, E.J.; Latter, A.M.; Ramsden, C.A. Melanogenesis-targeted anti-melanoma pro-drug development: Effect of side-chain variations on the cytotoxicity of tyrosinase-generated ortho-quinones in a model screening system. Eur. J. Cancer 1997, 33, 135-143. [CrossRef]

26. Krol, E.S.; Bolton, J.L. Oxidation of 4-alkylphenols and catechols by tyrosinase: Ortho-substituents alter the mechanism of quinoid formation. Chem.-Biol. Interact. 1997, 104, 11-27. [CrossRef]

27. Bolton, J.L.; Pisha, E.; Shen, L.; Krol, E.S.; Iverson, S.L.; Huang, Z.; van Breemen, R.B.; Pezzuto, J.M. The reactivity of o-quinones which do not isomerize to quinone methides correlates with alkylcatechol-induced toxicity in human melanoma cells. Chem.-Biol. Interact. 1997, 106, 133-148. [CrossRef]

28. Sugumaran, M.; Bolton, J. Direct evidence for quinone-quinone methide tautomerism during tyrosinase catalyzed oxidation of 4-allylcatechol. Biochem. Biophys. Res. Commun. 1995, 213, 469-474. [CrossRef] [PubMed]

29. Thörneby-Andersson, K.; Sterner, O.; Hansson, C. Tyrosinase-mediated formation of a reactive quinone from the depigmenting agents, 4-tert-butylphenol and 4-tert-butylcatechol. Pigment Cell Melanoma Res. 2000, 13, 33-38. [CrossRef]

30. Muñoz-Muñoz, J.L.; Garcia-Molina, F.; Varon, R.; Garcia-Ruíz, P.A.; Tudela, J.; Garcia-Cánovas, F.; Rodríguez-López, J.N. Suicide inactivation of the diphenolase and monophenolase activities of tyrosinase. IUBMB Life 2010, 62, 539-547. [CrossRef] [PubMed] 
31. Miyaji, A.; Gabe, Y.; Kohno, M.; Baba, T. Generation of hydroxyl radicals and singlet oxygen during oxidation of rhododendrol and rhododendrol-catechol. J. Clin. Biochem. Nutr. 2017, 60, 86-92. [CrossRef] [PubMed]

32. Sasaki, M.; Kondo, M.; Sato, K.; Umeda, M.; Kawabata, K.; Takahashi, Y.; Suzuki, T.; Matsunaga, K.; Inoue, $\mathrm{S}$. Rhododendrol, a depigmentation-inducing phenolic compound, exerts melanocyte cytotoxicity via a tyrosinase-dependent mechanism. Pigment Cell Melanoma Res. 2014, 27, 754-763. [CrossRef] [PubMed]

33. Suzuki, K.; Yagami, A.; Matsunaga, K. Allergic contact dermatitis caused by a skin-lightening agent, 5,5'-dipropylbiphenyl-2,2'-diol. Contact Dermat. 2012, 66, 51-52. [CrossRef] [PubMed]

34. Roberts, D.W.; Aptula, A.O. Allergic contact dermatitis caused by a skin-lightening agent, 5,5'-dipropylbiphenyl-2,2'-diol. A comment. Contact Dermat. 2012, 66, 357-359. [CrossRef] [PubMed]

35. Yagami, A.; Suzuki, K.; Sano, A.; Takahashi, M.; Kobayashi, T.; Morita, Y.; Ando, A.; Iwata, Y.; Matsunaga, K. Rhododendrol-induced leukoderma accompanied by allergic contact dermatitis caused by a non-rhododendrol skin-lightening agent, 5,5'-dipropylbiphenyl-2,2'-diol. J. Dermatol. 2015, 42, 739-740. [CrossRef] [PubMed]

(c) 2017 by the authors. Licensee MDPI, Basel, Switzerland. This article is an open access article distributed under the terms and conditions of the Creative Commons Attribution (CC BY) license (http:/ / creativecommons.org/licenses/by/4.0/). 